SHS Web of Conferences 12, 01007 (2014)

DOI: $10.1051 /$ shsconf $/ 20141201007$

C) Owned by the authors, published by EDP Sciences, 2014

\title{
Mobile Tourism Guide in the Context of Thai National Parks: The Effects of Mobile Design Qualities in TAM2
}

\author{
Numtip Trakulmaykee ${ }^{1}$, Parichard Benrit ${ }^{2}$ \\ ${ }^{1}$ Faculty of Science (ICT), Prince of Songkla University, 90112 Songkla, Thailand \\ ${ }^{2}$ Faculty of Humanities and Social Sciences, Prince of Songkla University, 94000 Pattani, Thailand
}

\begin{abstract}
This study aims to predict the level of international tourists' intention to use MTG in the context of Thai national parks, and investigates the roles of mobile design qualities (content quality, appearance quality, and interaction quality) through perceived usefulness and perceived ease-of-use on intention. The mixed-method via exploratory sequential design is conducted this study. The qualitative approach is started in the first stage then quantitative approach is employed to analyze the large sample size. This study extends the TAM2 with mobile design qualities. The results shows the high level of international tourist' intention to use MTG. It indicates that the international tourists will intent to the mobile tourism guide (MTG), if the MTG is provided for them. The direct factors of tourists' intention are perceived usefulness, perceived ease-of-use, mobile content quality and mobile appearance quality. The most direct effect is mobile content quality. The qualities of content and appearance have the positive roles on perceived usefulness, while the qualities of appearance and interaction have the indirect effects through perceived ease-of-use on tourists' intention. The proposed model provides the body of knowledge in the context of MTG, especially the factors of international tourists' intention to use MTG.
\end{abstract}

\section{Introduction}

Nowadays mobile applications are growing rapidly in a variety of contexts. Several industries focus on mobile adoption to take the advantages in their marketing. In the context of Thai national parks, mobile tourism guide (MTG) should be considered to be an additional information technology (IT) for international tourists. Due to the number of international tourists visiting Thai national parks is very small (8\% in year 2010) when compares with the total number of international tourists visiting Thailand. Tourism Authority of Thailand (TAT) points out that one of the strategies in tour promotion and conservation is to provide tour information for tourists. However, the MTG in the context of Thai national parks is a new technology and lack of guidance for development and adoption in particular of the users' perception and mobile design qualities. Therefore, this study conducts mixed method research in order to find out the current problems of Thai national parks and users' requirement in the first stage. Then, the quantitative approach is conducted to investigate the level of international tourists' intention to use MTG, and examine the direct and indirect factors of intention to use MTG. 


\section{Research Model and Hypotheses}

In order to predict intention to use MTG, we developed the research model based on Technology Acceptance Model 2 (TAM2) and extended the model by mobile design qualities (content quality, appearance quality, and interaction quality). The TAM2 has been a well-researched area in the IT field and it extends TAM by external variables of perceived usefulness (PU) and perceived ease-of-use (PEU). In addition, PU and PEU are the factors of intention to use IT in several contexts. [1] uncovered the social influence and cognitive instruments (job relevance, image, output quality and result demonstrability) as external variables of PU and PEU. However, there are several external variables of PU and PEU related to users' intention to use IT and should be considered in behavioral intention. Especially, mobile design qualities in mobile IT contexts are the possible impact on PU and PEU, as a result of small screen and limited interaction. Thus, this study focused on mobile design qualities as the external variables of PU and PEU.

Perceived usefulness is defined as the degree to which a person believes that using a particular system would enhance his/her job performance [1]. As most empirical studies found PU has a positive influence on users' intention to use technology. [2] reported the influence of perceived usefulness on intention using m-coupons. Similarly, [3] found that the higher perceived usefulness will increase the attitude to use mobile technology and indirectly increase users' intention to use mobile technology in travel. Based on this contention, the first hypothesis is:

H1: Perceived usefulness has a positive impact on intention to use MTG.

Perceived ease-of-use is defined as the degree to which a person believes that using a particular system would be free of effort [1]. In the mobile-based context, most empirical studies found the significant role of PEU on users' intention to use mobile applications. [2] identified PEU had a positive influence the behaviour and intention of consumers in using m-coupons. Likewise, [4] found that ease-of-use is an important factor significantly influencing mobile users' adoption of multimedia message service. In the context of MTG, this study believed that the higher PEU will increase users' intention. Thus, this study hypothesizes that:

H2: Perceived ease-of-use has a positive impact on intention to use MTG.

The content quality has been emphasized in IT adoption and mobile IT adoption. Mobile content quality is defined as the quality of the content provided by the mobile application to satisfies users' needs [5]. [6-7] revealed that content quality is an important issue of information system success. In the context of tour information services, the information quality also has a significant effect on usage intention[8]. Furthermore, [9] indicated that the content quality is an added value of benefit on mobile services which users expect to receive in their usage. Thus, this study supposes that mobile content quality has a possible impact on intention and PU in the context of MTG. The hypothesis is proposed as follows:

H3: Mobile content quality has a positive impact on intention to use MTG.

H4: Mobile content quality has a positive impact on PU.

The appearance quality is critical helping to meet users' expectation on mobile application because the small screen and inconvenient input [10]. The mobile appearance quality is defined as the degree of clear and understandable presentation on mobile screen [7]. [11] demonstrated in their study that appearance design and interface style should be considered based on target users. Likewise, [12] reported the important role of perceived appearance quality on mobile application that will affect users' willingness to buy and price willingness to pay via perceived value. Thus, this study believes that the mobile appearance quality has the impact on intention, PU and PEU in context of the MTG and hypothesizes as follows:

H5: Mobile appearance quality has a positive impact on intention to use MTG.

H6: Mobile appearance quality has a positive impact on PU.

H7: Mobile appearance quality has a positive impact on PEU.

The interaction quality is considered as an important usability issue because the input device on the small screen demands a high level of efforts while interacting with mobile devices $[10,13]$. User will perceive much more easily in terms of usage and learning when the mobile applications and mobile services are provided a good quality of interaction [14]. [15] highlighted that user will move to 
the other applications which are more easy to use, if they found application is difficult. Thus, this study expects that the higher mobile interaction quality will increase users' intention and PEU. The following hypotheses are proposed:

H8: Mobile interaction quality has a positive impact on intention to use MTG.

H9: Mobile interaction quality has a positive impact on PEU.

\section{Research Methodology}

This research used a mixed-method via exploratory sequential design. In the first stage, the qualitative approach using interview technique was conducted to capture users' requirements and understand current situations in Thai national parks. The findings from qualitative results are used to design and develop the MTG prototype. Next, the quantitative approach with a large sample is employed to generalize results to a population. Finally, the results from both approaches were explained together in terms as discussions and contributions as presented in Figure 1.

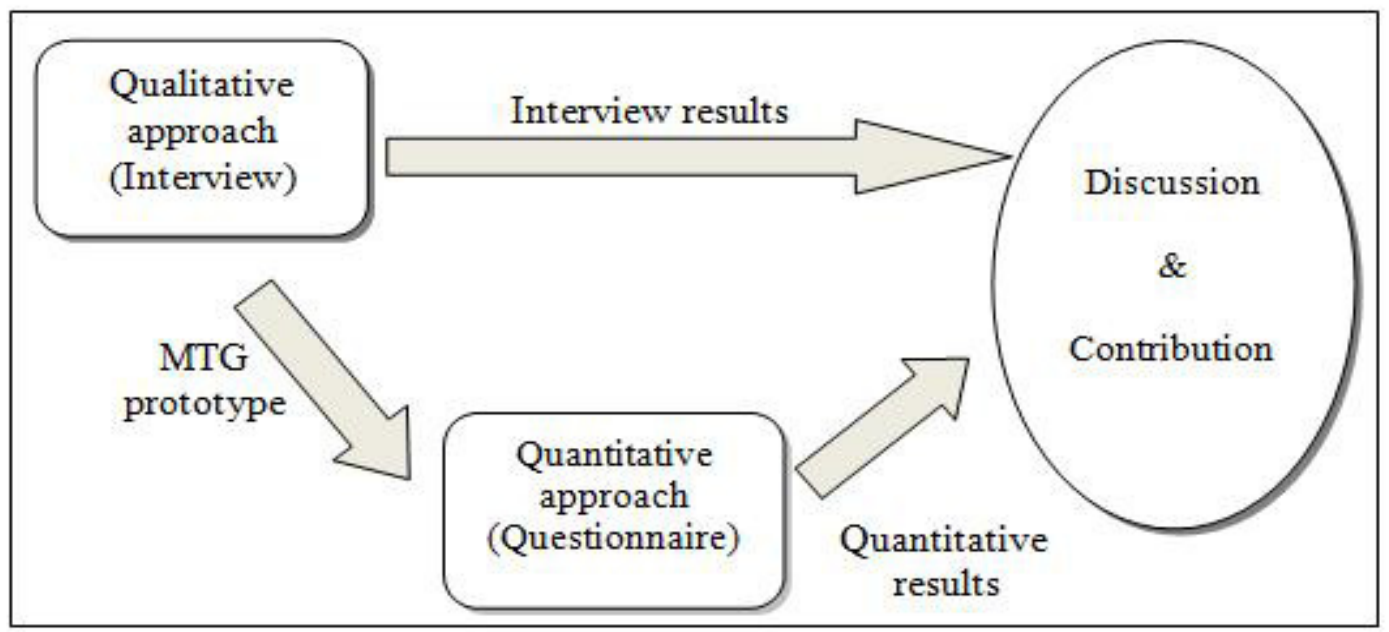

Figure 1. The Procedure of Mix Method in This Study.

\subsection{Qualitative Approach}

Interview technique is very useful in the early stage of research to reveal in-depth information from individual. [16-17] stated that interview technique can provide the opportunity for feedback and clarification, probing complex answers, and exhibiting the new prototype or pictures. Thus, this study employed the interview to collect the qualitative data in the purposes of: (1) to understand the national parks' problems and opinions about MTG from head officers of national parks and international tourists, and (2) to exhibit the list of tour contents and get users' requirements for developing MTG prototype. In this study, the interviewees consisted of two groups such as head officers of Thai national parks and international tourists. The head officers from top-five famous Thai national parks and bottom-famous Thai national parks were interviewed in this study. For international tourists' interview, ten participants were selected by convenience sampling at Doi Suthep National Park and Doi Innthanon National Park. Their nationalities are Chinese, Malaysian, Japanese, Austrian, Indian, American, Canadian, British, Dutch and Australian. 


\subsection{Quantitative Approach}

The study employed self-administered questionnaire for data collection. All measures were adapted from good reliable items, which Cronbach's alpha values exceed 0.70 . The items for measuring perceived usefulness were adapted from [5, 18], while items of perceived ease-of-use were adapted from $[5,19]$. For mobile content quality and mobile appearance quality, items were adapted from [20]. Meanwhile, items of mobile interaction quality were adapted from [13] and items of intention to use MTG were adapted from [3]. All items were anchored on a 7-point Likert scale which ranged from $1=$ strongly disagree to $7=$ strongly agree. Before data collection, the study conducted pilot test in order to ensure the effective questionnaires. In pilot test, the questionnaires were distributed to 30 convenient international tourists at Suvarnabhumi Airport in Thailand. The questionnaires were distributed to respondents using convenience sampling technique. The respondents in this study participated voluntarily. They were the international tourists at Departed International Hall in Suvarnabhumi Airports of Thailand in May, 2012. Before filling out the questionnaire, respondents were given the demonstration of MTG usage and MTG features; and then they had a chance to try out the MTG. The total number of completed questionnaires is 708 . Therefore, the data of this study is proper for analysis and testing in terms of reliability, validity, and research model [21]. Among 708 valid respondents, $54.5 \%$ were males, and $45.5 \%$ were females. The majority $(69.8 \%)$ of the collected samples was from 11 to 40 years old. As for the income background, $47.0 \%$ of respondents had an annual income greater than USD40,000, while others had annual income less than USD40,001 (53.0\%). In terms of respondent's continents, 354 (54.5\%) were Asian, 193 (27.3\%) came from Europe, 37 (5.2\%) came from Oceania, $6(0.9 \%)$ came from Africa, and 25 (3.5\%) came from Middle East.

\section{Data Analysis and Results}

\subsection{Qualitative Results}

In qualitative study, all head officers of Thai national parks suggested the similar list of tour contents which should be provided in the MTG. For example, Thai national parks' policy, entrance fee, closed period, attractive places, trekking map, flora and fauna, accommodations, transportation, activities, natural conservation, and emergency phone number. Meanwhile, international tourists suggested that the tour content should not provide only information about Thai national parks. As a result of tour behaviour, international tourists spend their time for travel more than 3 days in Thailand and visit more than two attractive places. Therefore, the MTG should be provided the other tour contents such as tour around city, public transportations, popular places in Thailand, restaurant recommendations, Do (s) and Do not (s) in Thailand, Thai living, Thai culture, Thai festivals, Thai fruit, Thai food, simple Thai dialogs for international tourists, climate, and money exchanged rate. In addition, international tourists suggested that the most tour contents in MTG should not require internet connection during usage because they cannot use free WIFI anywhere and most of them do not want to pay any internet fee. Likewise, head officers of Thai national parks highlighted that tourists cannot connect internet in everywhere in Thai national parks which the large area cover with forest.

\subsection{Quantitative Results}

A confirmatory factor analysis was conducted to further examine the measurement and research mode by WarpPLS software. The WarpPLS is the powerful Structural Equation Modelling (SEM) software to analysis data in Partial Least Squares (PLS) approach. 


\subsubsection{Measurement Analysis}

The reliability and validity are established by factor loading, composite reliability (CR), average variance extracted (AVE), and variance inflation factors (VIF) as presented in Table 1. The factor loadings of all items also are higher than 0.60 , which consider to be acceptable measurement for the construct [22]. The AVE of each construct is above 0.50 , thus the convergent validity of this study is adequate. In order to assess the reliability of a measurement items, the study computed the CR to assess the internal consistency. The CR values in this study range from 0.93 to 0.97 , which indicate the reasonable reliability level $(\mathrm{CR}>0.7)$ for the measured items.

Table 1: Reliability and Validity of Study

\begin{tabular}{llccc}
\hline Construct & \multicolumn{1}{c}{ Item } & Loading & CR & AVE \\
\hline Perceived & The MTG will make it easier to get travel information & 0.82 & 0.93 & 0.77 \\
Usefulness & The MTG will save my time for travel planning & 0.92 & & \\
(PU) & The MTG will enhances my effectiveness on travel & 0.87 & & \\
& The MTG will help me to find information quickly & 0.89 & & 0.92 \\
\hline Perceived & Learning to use the MTG is easy for me & 0.95 & & \\
ease-of-use & The MTG is easy to use & 0.94 & & \\
(PEU) & The MTG does not require a lot of effort & 0.93 & & \\
& The MTG's usage is clear & 0.86 & 0.93 & 0.78 \\
\hline Mobile & The MTG has the sufficient tour contents & 0.89 & & \\
content quality & The contents of MTG are up-to-date & 0.90 & & \\
(MCQ) & The contents of MTG are complete & 0.88 & 0.89 & 0.80 \\
& The contents of MTG are accurate & 0.89 & & \\
\hline Mobile & The MTG's design is attractive & 0.91 & & \\
appearance & The MTG has an appropriate font size and color & 0.92 & & \\
quality & The layout of MTG is appropriate & 0.91 & 0.95 & 0.82 \\
(MAQ) & The MTG provide the proper multimedia & 0.94 & & \\
\hline Mobile & The menus of MTG are well categorized & 0.91 & & \\
interaction & I am easy to know which's menu I am using in MTG & & \\
quality (MIQ) & I am easy to move back the previous page in MTG & & \\
& The navigation (links and buttons) is consistent design & 0.87 & & \\
\hline Intention to & If I have the MTG, I will use it for planning my trip & 0.89 & 0.93 & 0.77 \\
use MTG & If I have the MTG, I will use it during my trip & 0.90 & & \\
(INU) & If I have the MTG, I will use it for sharing experiences & 0.79 & & \\
& If I have the MTG, I will use it for the next trip & 0.92 & & \\
\hline
\end{tabular}

The mean value of international tourists' intention to use MTG is very high (6.32). It indicates that the international tourists will intent to the MTG when they have a chance to use it. Discriminant validity is tests correlations between constructs. To test the discriminant validity, the values of square root of AVE were computed as diagonal elements. These values should exceed the inter-construct correlations for adequate discriminant validity. As Table 2 shown, all correlation of constructs are significant $(p<0.01)$, and all diagonal elements were larger than their corresponding correlation coefficients. Therefore, the discriminant validity of study is acceptable. The VIF of each construct is less than the acceptable cut-off points of value 5 [22]. It indicates this study does not have any multicollinearity problem. 
Table 2. Descriptive Statistics and Correlation Analysis.

\begin{tabular}{lccccccccc}
\hline & Mean & S.D. & VIF & PU & PEU & MCQ & MAQ & MIQ & INU \\
\hline PU & 6.29 & 0.71 & 2.52 & $\mathbf{0 . 8 8}$ & & & & & \\
PEU & 6.56 & 0.57 & 2.31 & $0.65^{* *}$ & $\mathbf{0 . 9 3}$ & & & & \\
MCQ & 5.99 & 0.84 & 2.66 & $0.68^{* *}$ & $0.51^{* *}$ & $\mathbf{0 . 8 8}$ & & & \\
MAQ & 6.50 & 0.59 & 2.72 & $0.60^{* *}$ & $0.56^{* *}$ & $0.64^{* *}$ & $\mathbf{0 . 9 0}$ & & \\
MIQ & 6.43 & 0.65 & 3.29 & $0.65^{* *}$ & $0.62^{* *}$ & $0.69^{* *}$ & $0.75^{* *}$ & $\mathbf{0 . 9 1}$ & \\
INU & 6.32 & 0.69 & 2.28 & $0.64^{* *}$ & $0.70^{* *}$ & $0.68^{* *}$ & $0.64^{* *}$ & $0.61^{* *}$ & $\mathbf{0 . 6 1}$ \\
${ }^{* *} p<0.01$ & & & & & & & & &
\end{tabular}

\subsubsection{Model analysis}

As shown in Figure 2, most paths exhibits a $p$-value less than 0.05 excepting the path of mobile interaction and intention. Thus, the hypotheses in this study are supported excepting H8. It indicates that the direct factors of international tourists' intention to use MTG are PU $(\beta=0.22, p<0.001)$, PEU $(\beta=0.10, p<0.05)$, mobile content quality $(\beta=0.35, p<0.001)$ and mobile appearance quality $(\beta=$ $0.26, p<0.001)$. In the context of MTG, the most direct effect on tourists' intention is mobile content quality and the mobile content quality also has the positive roles on $\mathrm{PU}(\beta=0.50, p<0.001)$. Meanwhile, the mobile interaction quality has the indirect effect through $\operatorname{PEU}(\beta=0.57, p<0.001)$ on tourists' intention, and mobile appearance quality has the indirect effect through $\mathrm{PU}(\beta=0.28, p<$ $0.001)$ and PEU $(\beta=0.21, p<0.01)$. The result also reveals that the proposed model can explain $56 \%$ of the variation in the international tourists' intention to use MTG.

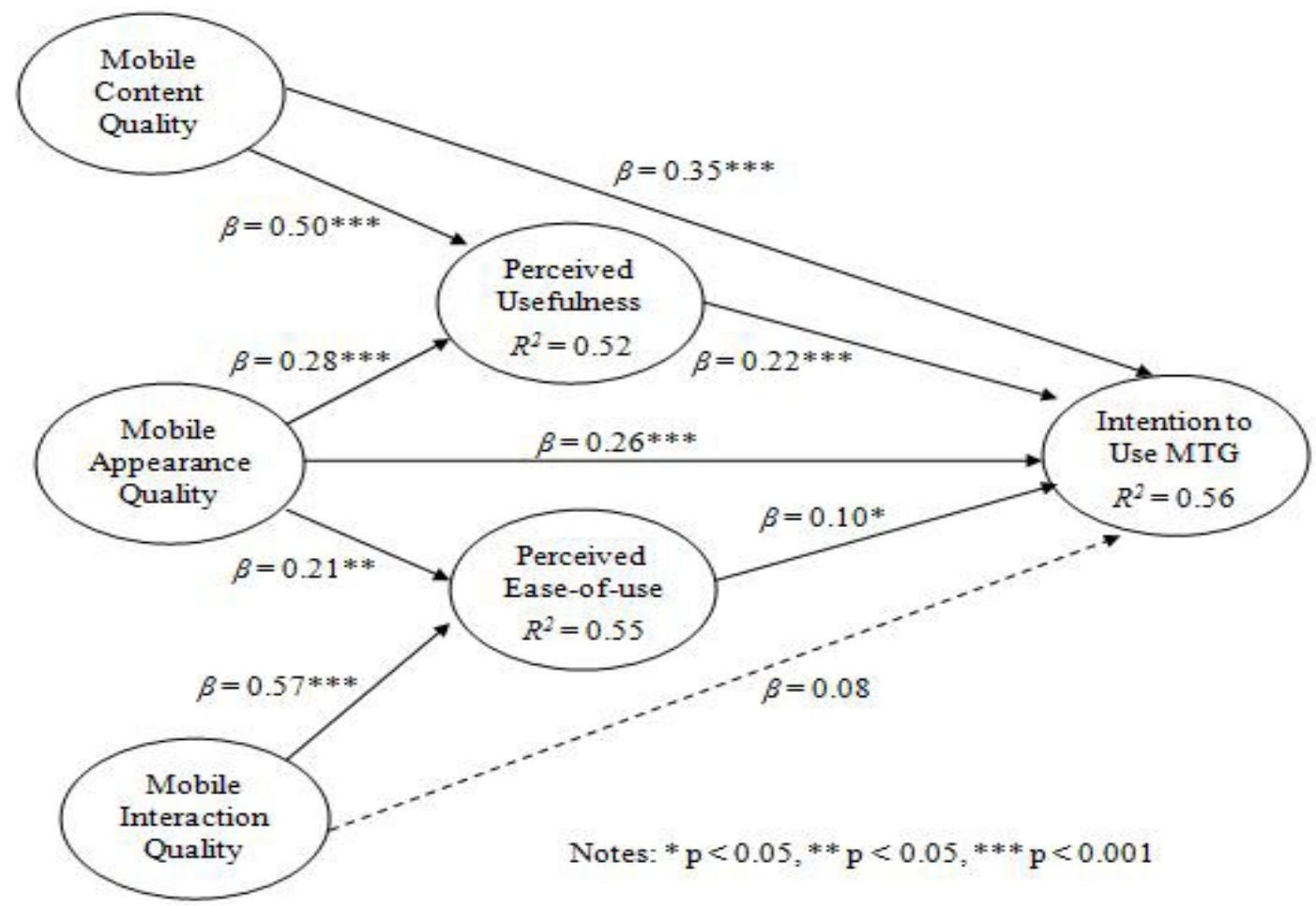

Figure 2. The Results of This Empirical Study. 


\section{Discussion and Conclusion}

Based on the obtained results, it indicates that international tourists will intent to use the MTG for their travel in the context of Thai national parks. The level of their intention is very high, although most tour contents in the MTG are static contents and no required internet connection likes the popular mobile tour applications (e.g., TripAdvisor and Lonely Planet). Due to most international tourists cannot access internet via mobile devices anywhere and anytime during their travel, especially in the forest area of Thai national parks. This finding is supported by the interview results from head officers of Thai national parks and international tourists. With regard to intention to use and TAM2, the findings confirms the positive influences of PU and PEU on intention to use MTG similar to the mobile studies of [2] and [4]. More specifically, this study reveals that qualities of content and appearance have the stronger effects on users' intention to use mobile application than PU and PEU. Likewise, $[7,10]$ highlighted that qualities of content and appearance are the critical helping to meet users' expectation on mobile applications. In terms of mobile interaction quality, this study did not found direct effect of mobile interaction quality on users' intention. It is contrary to the finding of study by [13]. However, the result reported that mobile interaction quality has the strong impact on PEU supported by [15] who highlighted the association of ease-of-use and interaction on mobile applications. Among direct factors of intention, the PEU has the least direct impact on intention. The possible reason is that today most mobile users are familiar to use mobile applications, thus the ease of learning and usage less influence on their intention to use mobile applications than the past.

Overall, this study has several contributions in terms of theoretical and practical aspects. From the theoretical perspective, this study proposes the novel framework for predicting international tourists' intention to use mobile IT in the context of national park. From the practical perspective, this study provides the development guidelines for mobile IT providers. As a result of the strong influences in both direct and indirect effects, mobile IT providers should focus on mobile content quality and mobile appearance quality by providing sufficient and accurate contents based on users' needs and ability of internet connection. In addition, they should design screen by providing attractive layout and proper mixed multimedia (e.g., photo, text, audio and video).

\section{Limitation and Future Work}

The international tourists in this study constitute a significant percentage of arrival international tourists in Thailand. Therefore, the study may expose more meaningful and useful results, if the future work studies in the other countries which the percentage of arrival international tourists is similar the percentage in Thailand. Furthermore, the intention to use MTG may differ in various countries. Thus, the future studies should concentrate on cross-cultural analysis to use the MTG among various continents and countries.

\section{References}

1. V. Venkatesh, F.D. Davis, Management Science, 46, 18 (2000)

2. S. Jayasingh, U.C. Eze, IJBI, 4, 22 (2009)

3. D.Y. Kim, J. Park, A.M. Morrison, International Journal of Tourism Research, 10, 15 (2008)

4. S.E. Chang, Y.H.V. Pan, BIT, 30, 15 (2011)

5. B.G. Kim, et al. ICMB-GMR,Athens, 9 (2010)

6. W.H. DeLone, E.R. McLean, Information Systems Research, 3, 36 (1992)

7. K.C. Lee, N. Chung, Interacting with Computers, 21, 8 (2009)

8. D.J. Kim, Y. Hwang, Information Systems Frontiers, 13 (2012)

8. J. Kim, K. Ahn, N. Chung, APJTR, 21 (2012)

9. S. Nikou, et al. EuroCPR, Budapest, 14 (2011)

10. T. Zhou, Internet Research, 21, 14 (2011)

11. C.H. Chen, C.Y. Tsai, Usability and Internationalization (Spinger, New York, 2007) 
12. H.Y. Ho, M.H. Lu, P.C. Lin, Pak. J. Statist, 29, 20 (2013)

13. M. Chae, et al., Electronic Markets, 12, 9 (2002)

14. M. Salo. HICSS, Hawaii, 10 (2013)

15. I. Ion, A. Zamfiroiu, Informatica Economica, 15, 17 (2011)

16. B. Wrenn, R.E. Stevens, D.L. Loudon, Marketing Research: Text and Cases (Haworth Press, New York, 2006)

17. W.E. Saris, I.N. Gallhofer, Design, Evaluation, and Analysis of Questionnaires for Survey Research (John Wiley \& Sons, New Jersey, 2007)

18. J.C. Gu, S.C. Lee, Y.H. Suh, Expert Systems with Applications, 36, 17 (2009)

19. C.Y. Tsai, African Journal of Business Management, 4, 9 (2010)

20. Y.S. Wang, Y.W. Liao, Computers in Human Behavior, 23, 8 (2007)

21. U. Sekaran, R. Bougie, Research Methods for Business: A Skill Building Approach (John Wiley \& Sons, UK, 2010)

22. J.F. Hair, et al., Multivariate Data Analysis (Pearson Prentice Hall, New Jersey, 2010) 